\title{
Improvement in Smooth Pursuit Eye Movements after Cigarette Smoking in Schizophrenic Patients
}

\author{
Ann Olincy, M.D., M.P.H., Randal G. Ross, M.D., David A. Young, Ph.D., \\ Margaret Roath, M.S.W., and Robert Freedman, M.D.
}

This study examined whether schizophrenics' cigarette smoking normalized smooth pursuit eye movement abnormalities. Fifteen schizophrenic and 15 ronschizophrenic subjects abstained from their usual cigarette smoking for an average of $10 \mathrm{~h}$. Their baseline performance during a constant velocity smooth pursuit task was then assessed. The subjects smoked as much as they desired in a 10-min period and then were retested immediately postsmoking, and 10 and 20 min later. Smooth pursuit gain and the percentage of total eye movement due to various saccadic subtypes were computed using infrared oculography and computerized pattern recognition software. After smoking, smooth pursuit gain increased and the percentage of total eye movements due to leading saccades decreased significantly in the schizophrenic patients. There were no changes in the gain or leading saccades of nonschizophrenic subjects after smoking. Nicotinic receptor dysfunction may be a candidate mechanism for smooth pursuit eye movement abnormalities in schizophrenia.

[Neuropsychopharmacology 18:175-185, 1998]

(C) 1998 American College of Neuropsychopharmacology.

Published by Elsevier Science Inc.
KEY WORDS: Cigarette smoking; Nicotine; Smooth pursuit eye movements; Schizophrenia; Saccades

Physiological deficits found in schizophrenic patients and their relatives have been proposed to elucidate genetic and pathophysiological mechanisms in schizophrenia (Holzman et al. 1988; Clementz and Sweeney 1990). One of the most reproducible biological defects in schizophrenic patients is smooth pursuit eye movement (SPEM) dysfunction (Holzman 1.987; Abel et al. 1991; Friedman et al. 1991; Radant and Hommer 1992; Levy et al. 1993). SPEM abnormalities also occur at in-

From the Departments of Psychiatry (AO, RGR, MR, RF) and Preventive Medicine and Biometrics (DAY), Denver Veterans Administration Medical Center (AO, RGR, RF); and University of Colorado Health Sciences Center (AO, RGR, DAY, MR, RF), Denver, Colorado.

Address correspondence to: Ann Olincy, M D., M.P.H., Department of Psychiatry, Box C-268-71, University of Colorado Health Sciences Center, 4200 East Ninth Avenue, Denver, CO 80262.

Received March 3, 1997; revised May 8, 1997; accepted June 6, 1997. creased frequency in relatives of schizophrenic probands (Levy et al. 1983; Holzman et al. 1984; Clementz et al. 1992; Ross et al. 1996). Family studies have suggested that a single autosomally transmitted gene may largely account for SPEM deficits in schizophrenic patients and their relatives (Holzman et al. 1988; Grove et al. 1992). Such single-gene effects are generally expected to be manifest as a single protein defect. This protein could be a structural element, such as a cell membrane constituent, or a developmental element, such as a growth factor. However, as the abnormalities present in schizophrenia are primarily limited to the brain, a protein associated with neurotransmitter function, such as a receptor molecule, is also possible. Although there has been some pharmacological investigation of SPEM abnormalities (Levy et al. 1984; Abel and Hertle 1988; Friedman et al. 1992; Litman et al. 1994), none have pointed to a specific neurotransmitter defect.

Another physiological defect associated with schizophrenia, a deficit in the inhibitory gating of the P50- 
evoked response to repeated auditory stimuli, appears to be related to a specific nicotinic cholinergic receptor (Freedman et al. 1994). Evidence for" nicotinic receptor involvement includes: (1) reproduction of this auditoryevoked potential deficit in animal models by pharmacological blockade of the low affinity nicotinic cholinergic receptors (Luntz-Leybman et al. 1992); (2) decreased labeling of nicotinic receptors in post mortem brains of schizophrenic patients (Freedman et al. 1995); (3) normalization of the P50 deficit when schizophrenic patients and their relatives smoke cigarettes or are administered nicotine in the form of gum (Adler et al. 1992, 1993); and (4) linkage of the inheritance of the auditoryevoked potential deficit to a locus at the chromosome 15 site of the $\alpha 7$ nicotinic receptor (Freedman et al. 1997). Thus, a specific defect in a nicotinic receptor gene may be involved in the P50 abnormality.

The aim of the present study was to determine if nicotine also normalizes eye movement dysfunction in schizophrenic patients. As schizophrenic patients are often heavy smokers (Hughes et al. 1986) and the optimal dose to effect a possible improvement in SPEM was unknown, nicotine was administered by using the subject's self-chosen smoking patterns. This strategy allowed subjects to individually determine their number of cigarettes and their intensity of inhalation and therefore the dose of nicotine. Smoking was chosen as the route of administration as this method rapidly delivers nicotine, minimizing desensitization, to which the nicotinic receptor is particularly prone. Nonschizophrenic smokers, also chronically exposed to nicotine, served as a comparison group. Nicotine has a peak concentration in the brain at approximately $5 \mathrm{~min}$ after: inhalation (Benowitz et al. 1988). Therefore, eye tracking was performed several times post-cigarette exposure with the hypothesis that the maximum improvement in SPEM would be observed shortly after the 10-min smoking period and that the nicotine effect would diminish with time. A similar protocol omitting cigarette smoking served to control for repetition of the task.

\section{SUBJECTS AND METHODS}

\section{Subjects}

Subjects were recruited from the Denver VAMC and the Colorado Psychiatric Hospital inpatient and outpatient services. Diagnoses of the 15 schizophrenic smokers were confirmed using DSM-III-R (Arnerican Psychiatric Association 1987) criteria and chart review. The examiners were careful to rule out other possible causes of psychoses such as affective disorders, psychoactive substance abuse, and other psychotic disorders due to a general medical condition. Fifteen smoking comparison subjects were recruited. They were then screened using the Structured Clinical Interview for DSM-III-R, Nonpatient Edition (SCID-NP; Spitzer et al. 1990) and the Family History Research Diagnostic Criteria (FH-RDC; Endicott et al. 1978). Exclusion criteria included current or past psychoses, neurological disorders, or a family history of schizophrenia. As people with psychiatric diagnoses are more likely to be smokers, the nonschizophrenic subject group had two subjects with current psychiatric diagnoses, one with dysthymia and panic disorder with agoraphobia, and one with panic disorder without agoraphobia. There were also several nonschizophrenic subjects with past psychiatric diagnoses: four with diagnoses of past major depression, three with diagnoses of past alcohol or other substance dependence, and one with past panic disorder. The nonschizophrenic subjects with current or past psychiatric diagnoses were not different from the nonschizophrenic subjects without psychiatric diagnoses in any measured parameter of smooth pursuit eye movements. One nonschizophrenic subject was taking $75 \mathrm{mg}$ of imipramine for migraine headaches, otherwise, no other nonschizophrenic subjects were taking psychotropic medications. After complete description of the study to the subjects, written informed consent was obtained. Eleven $(73 \%)$ of the schizophrenic patients and five $(33 \%)$ of the nonschizophrenic subjects were male. The age of schizophrenic patients ranged from 22 to 64 years (mean \pm SD: $38.40 \pm 11.24$ ), and the age of the nonschizophrenic subjects ranged from 19 to 56 years (36.47 \pm 11.60$)$. The level of education for schizophrenic patients ranged from 11 to 18 years $(13.20 \pm 2.01)$, and the level of education of the nonschizophrenic subjects ranged from 12 to 22 years $(16.20 \pm 3.05)$. Thirteen $(87 \%)$ of the schizophrenic patients were paranoid, chronic subtype, the remaining two $(13 \%)$ were disorganized, chronic subtype. Two (13\%) of the schizophrenic patients were currently hospitalized, the other $13(87 \%)$ were outpatients. Six $(40 \%)$ of the schizophrenic patients were taking traditional neuroleptics, six $(40 \%)$ were taking clozapine, one $(7 \%)$ was taking both clozapine and a typical neuroleptic, and two (13\%) were taking no antipsychotic medication.

\section{Experimental Procedure}

The eye movement tracking procedure used has been previously described by Radant and Hommer (1992). Subjects were seated $46 \mathrm{~cm}$ in front of a video monitor on which a small target was displayed against a black background in an otherwise dark room. The subject's head was stabilized with a bite bar and a head rest. Horizontal eye movements were recorded using an infrared photoelectrode limbus detection eye tracking device, which is accurate within $0.25^{\circ}$ of visual angle and has a time constant of $4 \mathrm{~ms}$. The analog output of the 
device was sampled at $500 \mathrm{~Hz}$, using a 12-bit analog-todigital converter. Data were collected from the eye for which the most rapid and accurate calibration could be obtained.

The target moved horizontally back and forth over $30^{\circ}$ with a constant velocity of $16.7^{\circ} / \mathrm{s}$ and a $1.4-\mathrm{s}$ fixation period between ramps (a trapezoidal pattern). Subjects were told to keep their eyes on the target and follow it as best they could.

Subjects were asked to abstain from smoking after 11:00 P.M. the evening before the testirg. Subjects were then tested between 8:00 and 9:00 A.M. the next morning. Self-reported time of last cigarette was documented. As subjects smoked their last cigarette at different times before testing, abstinence times varied. After multiple attempts, two schizophrenic subjects were unable to abstain from smoking overnight; they abstained for 1.5 to $2.5 \mathrm{~h}$ during the day. The abstinence time of schizophrenic patients was mean $=11.12 \mathrm{~h}$, range $2-48$, on the smoking day and mean $=10.17 \mathrm{~h}$, range $1.5-14$, on the nonsmoking day. The abstinence time of the nonschizophrenic subjects was mean $=9.42 \mathrm{~h}$, range $8-10.5$, on the smoking day and mean $=10.17 \mathrm{~h}$, range $9-17$, on the nonsmoking day. There were no significant differences in abstinence tirnes of the two groups on either the smoking $(t=-0.60, d f=27$, NS) or nonsmoking days $(t=0.86, d f=26$, NS). The subjects performed a baseline smooth pursuit task, then either waited $10 \mathrm{~min}$ without smoking or smoked as much as desired in a 10-min period. Subjects then repeated the same smooth pursuit task immediately, at $10 \mathrm{~min}$ and at $20 \mathrm{~min}$. Blood pressure and pulse were monitored after the baseline and the second trials. The order of the nonsmoking or smoking trials was randomly assigned and the trials were performed 1 week apart.

\section{Eye Movement Analysis}

All eye movement data were analyzed with a computerized pattern recognition program described by Radant and Hommer (1992) and visually inspected by the experimenter. Raw data consists of eye position and target position for each $2 \mathrm{~ms}$ of recorded tracking. Eye movements were divided into discrete segments, then each segment was classified as saccade, smooth pursuit, or artifact. Saccades were identified on the basis of peak velocity (greater than $35^{\circ} / \mathrm{s}$ ), initial acceleration (greater than $2000^{\circ} / \mathrm{s}^{2}$ ) and minimum duration ( $\geqslant 9 \mathrm{~ms}$ ). Segments not meeting velocity and acceleration criteria for saccades were considered smooth pursuit or fixation. Artifactual segments caused by eye blinks show distinct morphology and were removed from the analyses by pattern recognition software. Each ramp was individually calibrated for position of the target using the 1.4-s fixation points before and after target movement. Dur- ing trapezoidal tasks, eye movements during fixation or within $250 \mathrm{~ms}$ of a change in target motion were discarded for the analyses, as these movements may not represent normal pursuit (Lisberger and Pavelko 1989).

Overall task performance was measured by mean gain (weighted for time) of all intervals of true smooth pursuit (Abel et al. 1991). Intervals defined as saccades were not included in computing gain. Gain for a given interval of smooth pursuit was measured as mean velocity divided by target velocity during periods when the smooth pursuit system was used. Theoretical optimal performance on this task was defined as 1.0 (i.e., eye velocity $=$ target velocity; Abel et al. 1991).

Impaired smooth pursuit tracking can have at least two sources of error: (1) impairment in the smooth pursuit system causes a mismatch between eye velocity and target velocity requiring catch-up saccades to return gaze to target location; catch-up saccades were defined as saccades that were in the same direction as target motion, and either began behind target location and ended ahead of target location or decreased position error by at least $50 \%$; and (2) saccades can intrude on otherwise normal pursuit. Some of these intruding saccades appear to represent a subject's shift of gaze to future target location, and are termed "leading" saccades (previously referred to as small anticipatory saccades; the terminology was clarified at the suggestion of Drs. Philip Holzman and Deborah Levy). Leading saccades were defined as saccades that were in the same direction as target motion, either begun or ended ahead of target location or increased position error by $100 \%$, and were followed by a $50-\mathrm{ms}$ interval of eye velocity less than $50 \%$ of target velocity. The best measure of catch-up and leading saccades' total impact on smooth pursuit tracking is the percentage of total eye movements due to each saccadic type, a measure affected by both amplitude and frequency criteria (Ross et al. 1994). Thus, the percentage of total eye movement due to each saccadic subtype was calculated at $100 \times$ total amplitude of the saccadic subtype/[total amplitude of smooth pursuit + total amplitude of forward saccades (in the direction of target motion) - total amplitude of backward saccades (opposite target motion)].

Square-wave jerks are smaller saccades of unknown utility (Shallo-Hoffman et al. 1989). Square-wave jerks were defined as complexes of two saccades (of roughly similar size), in opposite directions, separated by an interval ( $50-500 \mathrm{~ms}$ ) of parafoveal smooth pursuit. As the net amplitude of square-wave jerks approaches zero, square-wave jerks were measured by their frequency, i.e., number of square-wave jerks per second of artifact free data calculated as [total time of smooth pursuit + total time of forward saccades (in the direction of target motion) + total time of backward saccades (opposite target motion)]. 


\section{Statistical Analysis}

The relationship between smoking and eye tracking was analyzed in two ways. First, differences in performance in baseline trials between and within groups were assessed using Student's $t$-tests. Second, to determine the effect of smoking on SPEM gain or any of the saccadic measures in either subject groups compared to their own baseline performance, the data were (1) assessed with a paired $t$-test with the a priori assumption that the change due to the nicotine would occur immediately after smoking in the smoking trial and no equivalent change would be noted in the nonsmoking trial; (2) plotted as a function of time relative to smoking or the equivalent waiting period, for analysis using the linear random-effects model of Laird and Ware (1982). Although all subjects were to complete both smoking and nonsmoking trials, three of the schizophrenic patients completed only one trial and refused further participation. In addition, on the smoking trial day, two schizophrenic patients had unusable data due to illness during the testing. Excessive artifacts caused loss of additional time points in both groups of subjects, but there were no significant differences in amount of data available for analysis between the schizophrenic patients and the nonschizophrenic subjects at any time point. A randomeffects design was chosen for analy'sis as this model is appropriate for repeated measures data and accommodates missing values. Constant or linear regression lines were fit to the data for each group, and the best-fitting lines validated with likelihood ratio tests (Seber and Wild 1989). The best-fitting model for each group was then superimposed on the means \pm SEM for visual inspection and interpretation. The data for gain, the percentage of total eye movements due to leading saccades, and the percentage of total eye movements due to catch-up saccades for nonschizophrenic subjects during both smoking and nonsmoking conditions were best modeled as constant values. The data for gain and the percentage of total eye movements due to leading saccades for schizophrenic patients during both nonsmoking conditions were best modeled as linear regression lines, and as constants during the smoking conditions. The data for the percentage of total eye movements due to catch-up saccades were best modeled as constants during smoking and nonsmoking conditions. The data for the square-wave jerks were best modeled as constants during smoking and nonsmoking conditions. Differences between values were assessed using Wald tests (Seber and Wild 1989).

A Fisher's Exact Test was used to assess differences between groups on the number of cigarettes smoked during the 10-min smoking period. Effects of number of cigarettes smoked, autonomic changes with smoking, and length of abstinence were assessed with Pearson correlation coefficients. The influence of the type of neuro- leptic medication on the changes in gain or saccades after baseline was assessed with an ANOVA. The critical level was set at $\alpha=0.05$, two-tailed, for all tests.

\section{RESULTS}

\section{Smoking}

Most subjects smoked from one to four cigarettes during the smoking trial. Schizophrenic patients were heavier smokers (mean $=1.12 \pm 0.69$ packs $/$ day, range $0.1-2.0$ ) than nonschizophrenic subjects (mean $=0.86 \pm$ 0.39 packs/day, range $0.25-2.0$ ) Nine of the 15 schizophrenic patients smoked two or more cigarettes in the 10 -min period, compared to only two of the 15 nonschizophrenic subjects (Fisher's Exact Test $=5.40, d f=$ $1, p<.02)$. Although the number of cigarettes smoked during the smoking trial was highly correlated with the average packs per day in the nonschizophrenic subjects, $(r=0.84, d f=15, p<.001)$, this was not the case in the schizophrenic patients $(r=0.21, d f=15, p=$ NS).

\section{Leading Saccades}

Schizophrenic patients had a significantly greater percentage of total eye movements due to leading saccades at baseline (mean \pm SD: $6.57 \pm 3.65$ ) than nonschizophrenic subjects $(2.85 \pm 3.75 ; t=-2.67, d f=26, p<$ .013) but no differences in number of large amplitude anticipatory saccades $(t=0.57, d f=24, p=\mathrm{NS})$. There were no differences between the baseline leading saccade percentages before the smoking and the nonsmoking trials within groups (schizophrenic patients $t=$ $0.42, d f=21, p=N S$; nonschizophrenic subjects $t=$ $-0.15, d f=21, p=N S$ ).

A significant effect of smoking on the percentage of total eye movements due to leading saccades was detected in the schizophrenic patient group. Cigarette smoking decreased leading saccades, yet had no similar positive effect on the nonschizophrenic subjects. Figure 1 shows the performance of a schizophrenic patient and a nonschizophrenic subject on a portion of the smooth pursuit task at baseline and immediately after smoking. The schizophrenic patient's percentage of total eye movements due to leading saccades decreased from 3.6 to 0.6 after smoking two cigarettes. The nonschizophrenic subject's percentage of total eye movements due to leading saccades increased slightly from 0.5 to 0.7 after smoking 1.5 cigarettes.

Schizophrenic patients' percentage of total eye movements due to leading saccades, immediately after smoking, significantly decreased compared to baseline performance (paired $t$-test $=-2.97, d f=10, p<.01$; Figure 2A). Without smoking, there was no such improvement in the percentage of total eye movements due to leading 


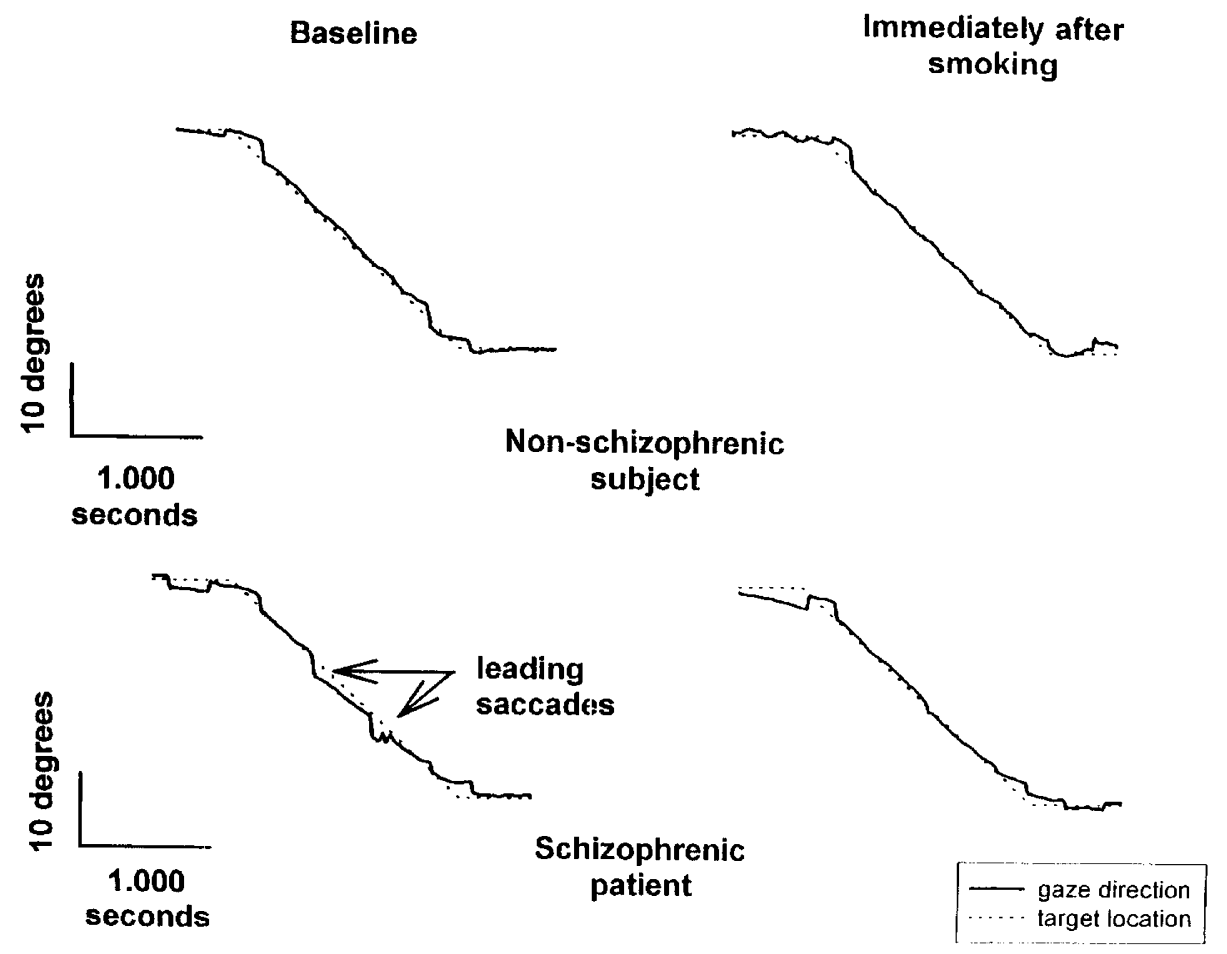

Figure 1. Performance of a schizophrenic patient and a nonschizophrenic subject on a portion of the smooth pursuit task at baseline and immediately after smoking.

saccades in the schizophrenic group (paired $t$-test $=$ $0.61, d f=9, p=N S$; Figure 2B). The schizophrenic patients' percentage of total eye movements due to leading saccades, immediately after smoking, was no longer significantly different from the nonschizophrenic subjects' percentage of total eye movement due to leading saccades $(t=-1.52, d f=23, p=N S)$. Schizophrenic patients in the nonsmoking trial showed a significant linear increase in percent of total eye movements due to leading saccades after baseline (Wald Test, $\chi^{2}=4.1, d f=$ $1, p<.05)$. This linear increase did not occur in the smoking trial. In contrast, nonschizophrenics' percentage of total eye movements due to leading saccades did not differ whether or not they smoked (Wald Test, $\chi^{2}=$ $0.36, d f=1, p=\mathrm{NS}$ ). Schizophrenic patients' percentage of total eye movements due to leading saccades after smoking became no different from the nonschizophrenic subjects' percentage of total eye movements due to leading saccades in the nonsmoking trial (Wald Test, $\chi^{2}=2.52, d f=1, p=$ NS; Figure 3).

\section{Smooth Pursuit}

Consistent with previous reports (Radant and Hommer 1992; Abel et al. 1991; Friedman et al. 1991), schizophrenic patients had significantly lower baseline gain (mean \pm SD: $0.80 \pm 0.07$ ) than nonschizophrenic subjects $(0.92 \pm 0.06 ; t=4.95, \mathrm{df}=26, \mathrm{p}<0.001)$. There were no differences between the baseline SPEM gain values before the smoking and the nonsmoking trials within group (schizophrenic patients $t=0.58, d f=21, p<.57$; nonschizophrenic subjects $(t=1.23, d f=21, p<.23)$.

A trend toward increased smooth pursuit gain with smoking was detected in the schizophrenic patient group. Cigarette smoking enhanced schizophrenic patients' ability to match target velocity, yet had no similar positive effect on the nonschizophrenic subjects. In Figure 1, the schizophrenic subject's gain increased from 0.86 to 0.94 after smoking two cigarettes. The nonschizophrenic patient's gain slightly increased from 0.93 to 0.96 after smoking 1.5 cigarettes.

Schizophrenic patients' gain, immediately after smoking, showed a slight but nonsignificant improvement compared to baseline performance (paired $t$-test $=1.88$, $d f=11, p<.09$ ). Without smoking, there was no such improvement in gain in the schizophrenic patient group (paired $t$-test $=0.33, d f=8, p=\mathrm{NS}$ ). Schizophrenic patients in the nonsmoking trial displayed a significant linear decrease in gain after baseline (Wald Test, $\chi^{2}=$ $10.3, d f=1, p<.002$ ). This linear decrease did not occur in the smoking trial. In contrast, nonschizophrenic subjects' gain did not significantly differ whether or not they smoked (Wald Test, $\chi^{2}=2.91, d f=1, p=N S$; Figure 4).

\section{Catch-up Saccades}

Schizophrenic patients also had a significantly greater percentage of total eye movement due to catch-up saccades at baseline (mean \pm SD: $18.00 \pm 4.47)$ than nonschizophrenic subjects $(10.33 \pm 4.56, t=4.41, d f=25$, 
$p<.001)$. There were no differences between the baseline catch-up saccade percentaged before the smoking and the nonsmoking trials within group (schizophrenic patients $t=-0.56, d f=21, p=N S$; nonschizophrenic subjects $t=-0.31, d f=21, p=N S$ ).

Schizophrenic patients' percentage of total eye movements due to catch-up saccades, imrnediately after smoking, showed no changes when compared to their baseline performance (paired $t$-test $=-0.13$, $d f=11, p=N S$ ). Without smoking, there was also no change in the percentage of total eye movements clue to catch-up sac-
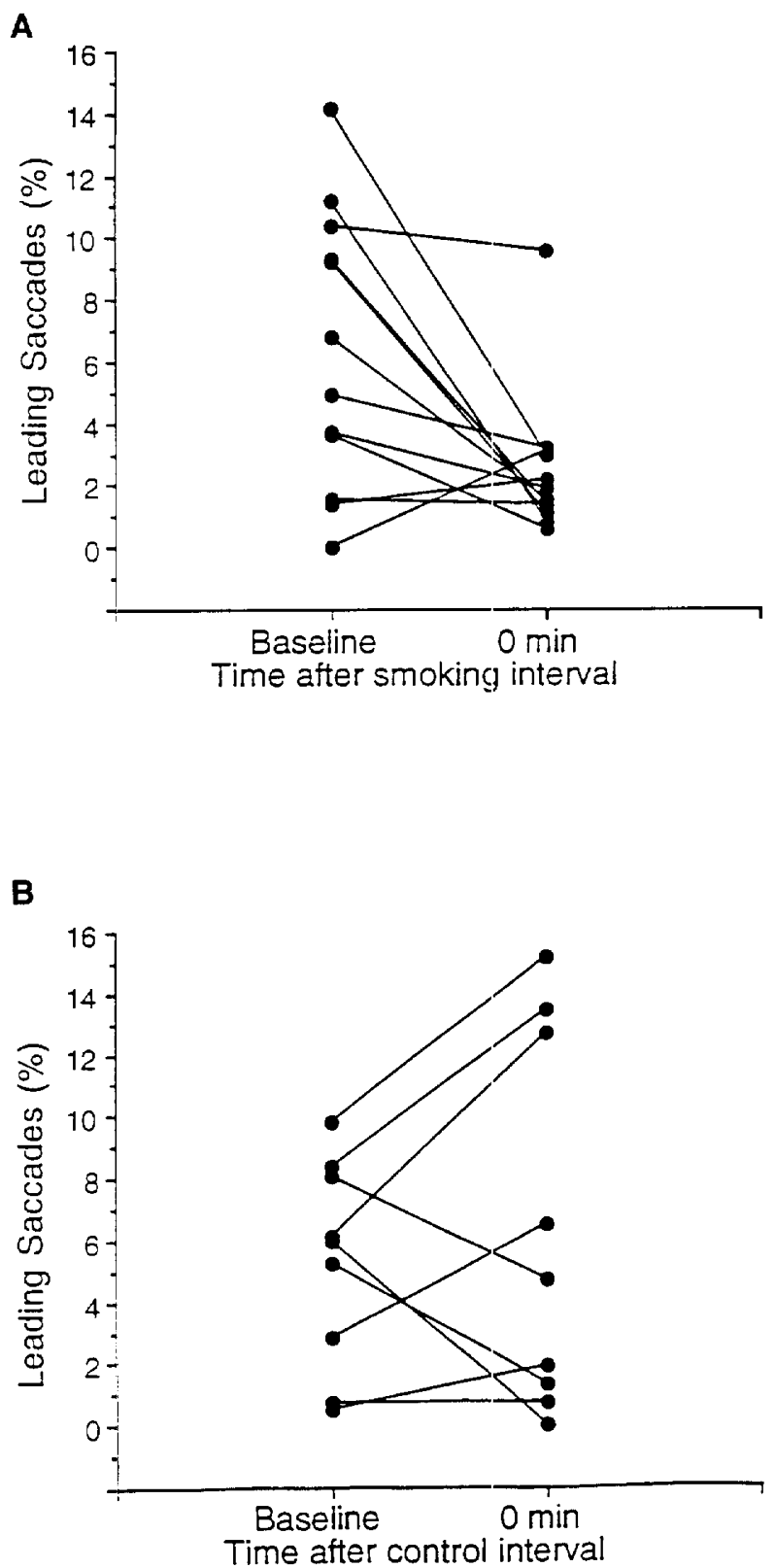

Figure 2. Percentage of total eye movements due to leading saccades at baseline and at 0 minutes for each schizophrenic patient: (A) smoking trial (B) nonsmoking trial.

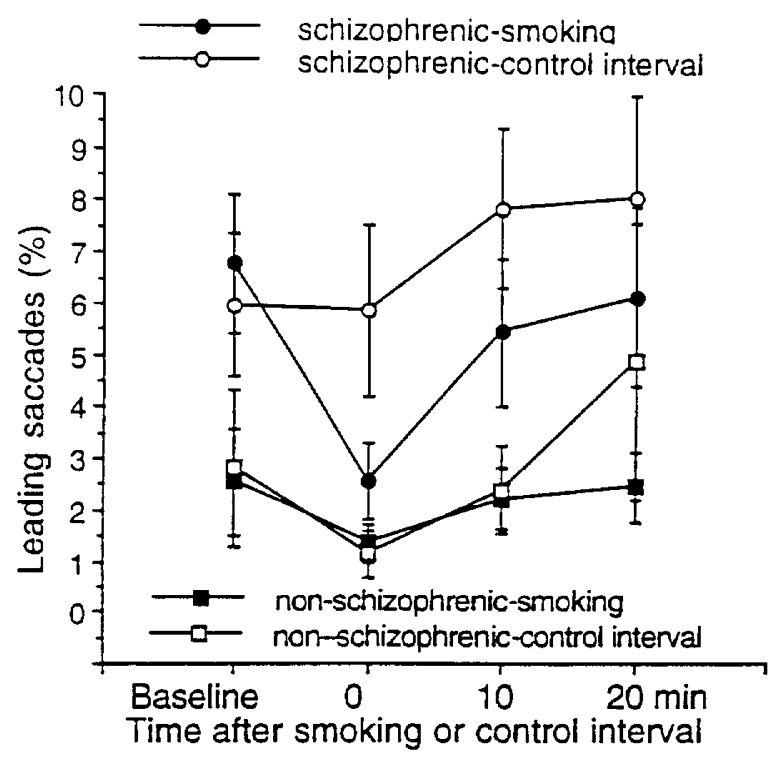

Figure 3. Percentage of total eye movements due to leading saccades (Mean \pm S.E.M.) at baseline, 0 minutes, 10 minutes and 20 minutes in schizophrenic patients and nonschizophrenic subjects after smoking or nonsmoking intervals.

cades in the schizophrenic group (paired $t$-test $=0.19$, $d f=8, p=$ NS). However, the schizophrenic patients had a significantly decreased percentage of total eye movements due to catch-up saccades with smoking at any time point (Wald Test, $\chi^{2}=4.56, d f=1, p<.04$ ). Schizophrenic patients with smoking were significantly different from nonschizophrenic subjects with smoking (Wald Test, $\chi^{2}=15.78, d f=1, p<.0001$ ) and from nonschizophrenic subjects without smoking (Wald Test, $\chi^{2}=$

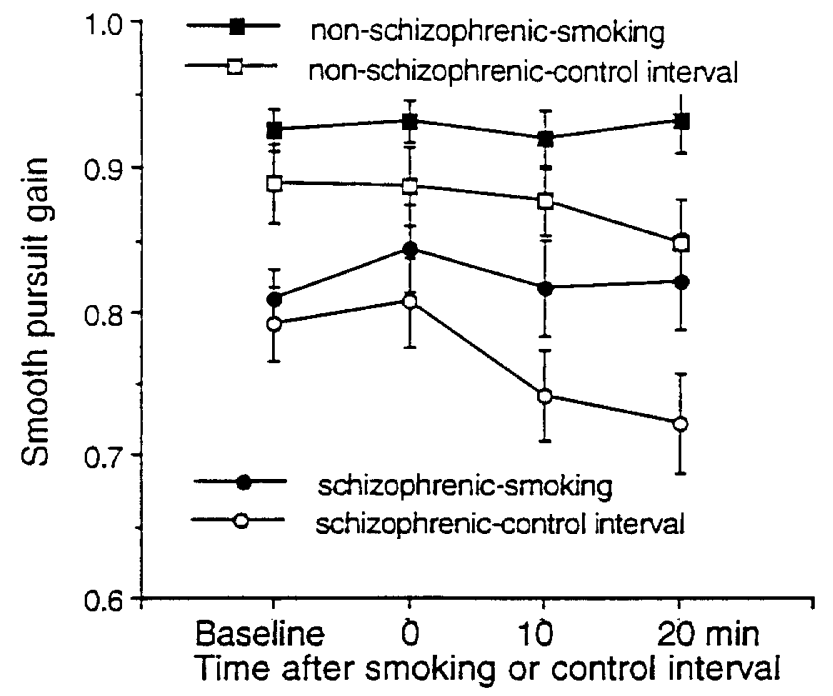

Figure 4. SPEM gain at baseline, 0 minutes, 10 minutes and 20 minutes in schizophrenic patients and nonschizophrenic subjects after smoking or nonsmoking intervals. 
23.82, $d f=1, p<.0001$ ). No effect of smoking on the percentage of catch-up saccades was detected in the nonschizophrenic subject group (Wald Test, $\chi^{2}=1.10$, $d f=1, p=$ NS; Figure 5)

\section{Square-Wave Jerks}

Schizophrenic patients had no differences in baseline frequency of square-wave jerks (mean \pm SD: $0.03 \pm$ $0.04)$ compared to nonschizophrenic subjects $(0.08 \pm$ $0.10 ; t=-1.70, d f=26, p=N S)$. There were also no differences between the baseline square-wave jerk frequency before the smoking and the nonsmoking trials within group (schizophrenic patients $t=1.85, d f=21$, $p=$ NS; nonschizophrenic subjects $t=1.86, d f=21, p=$ NS). For the group as a whole, schizophrenic patients' frequency of square-wave jerks, irnmediately after smoking, showed no changes when compared to their baseline performance (paired $t$-test $=0.22, d f=11, p=$ NS). Without smoking, there was also no change in frequency of square-wave jerks in the schizophrenic patient group (paired $t$-test $=1.52, d f=3, p=N S$ ). No effects of smoking on the frequency of square-wave jerks were detected in either the schizophrenic patient or the nonschizophrenic subject groups over time (schizophrenic patients Wald Test, $\chi^{2}=1.20, d f=1, p=$ NS; nonschizophrenic subjects Wald Test, $\chi^{2}=0.04, d f=1$, $p=$ NS; Figure 6).

\section{Other Parameters}

Length of abstinence was not correlated with the number of cigarettes smoked in the 10-min time period, with

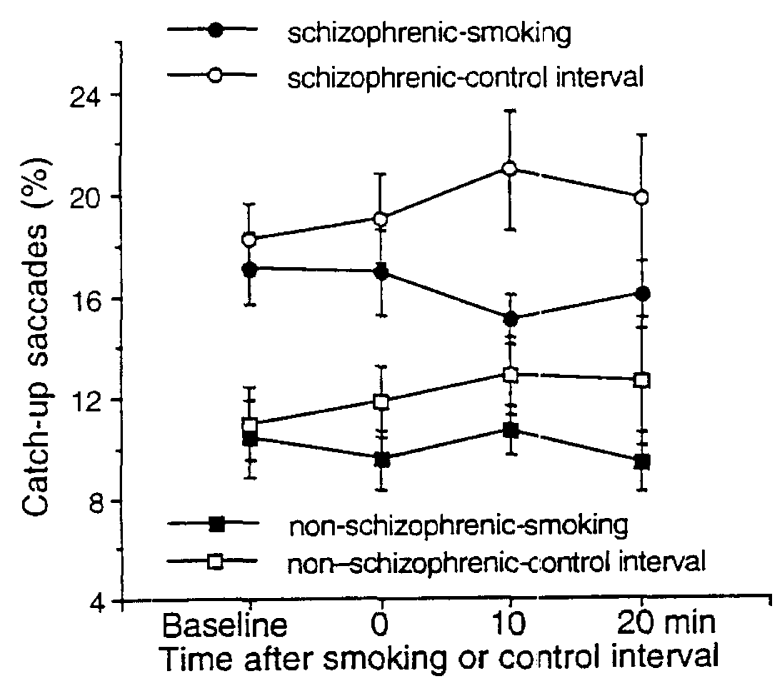

Figure 5. Percentage of total eye movements due to catchup saccades at baseline, 0 minutes, 10 minutes and 20 minutes in schizophrenic patients and nonschizophrenic subjects after smoking or nonsmoking intervals. the increase in gain from baseline, with the decrease in the percentage of total eye movements due to catch-up saccades from baseline, or with the decrease in the percentage of total eye movements due to leading saccades from baseline. The schizophrenic patients and nonschizophrenic subjects demonstrated similar changes in systolic blood pressure, diastolic blood pressure, and pulse with smoking, which indicated that the subject groups were not experiencing different amounts of autonomic withdrawal symptoms. There were no differences in coffee consumption between the schizophrenic patients or the nonschizophrenic subjects; coffee consumption did not occur within $1 \mathrm{~h}$ of testing.

Although a positive effect of nicotine on gain, the percentage of total eye movements due to catch-up saccades and the percentage of total eye movements due to leading saccades was only demonstrated in the schizophrenic patients, this group also smoked a greater number of cigarettes during the 10-min period. Schizophrenic patients are also known to get more nicotine from each cigarette (Olincy et al. 1997), presumably by deeper and more frequent inhalation. As the smoking interval was time limited, to smoke more cigarettes, deeper and more frequent inhalation was required. Thus, the number of cigarettes smoked may underestimate the level of nicotine achieved. Regardless, the number of cigarettes smoked was not a significant covariate in the changes in gain, percentage of total eye movements due to catch-up saccades, or percentage of total eye movements due to leading saccades from baseline in the smoking trial in the schizophrenic patients.

Although the number of subjects in each medication group was small, neuroleptic usage, whether atypical,

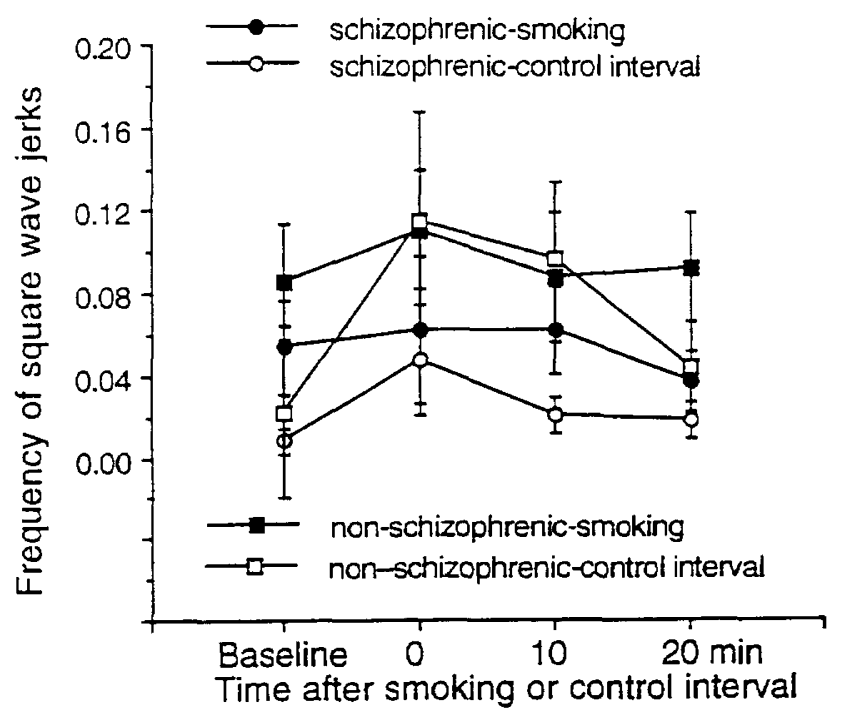

Figure 6. Mean \pm S.E.M. frequency of square-wave jerks at baseline, 0 minutes, 10 minutes and 20 minutes in schizophrenic patients and nonschizophrenic subjects after smoking or nonsmoking intervals. 
typical or none, did not influence postsmoking increase in gain $(\mathrm{F}=1.276, d f=2,9, p=\mathrm{NS})$ or postsmoking decrease in the percentage of eye movement due to leading saccades $(\mathrm{F}=3.20, d f=2,8, p=\mathrm{NS})$.

\section{DISCUSSION}

Schizophrenic patients demonstrated a trend toward improvement of their smooth pursuit gain, significantly decreased their percentage of total eye movements due to leading saccades, and significantly decreased their percentage of total eye movements due to catch-up saccades, after cigarette smoking. In contrast, nonschizophrenic subjects showed no effect of nicotine on smooth pursuit gain, the percentage of total eye movements due to leading saccades, or their percentage of total eye movements due to catch-up saccades. Possible explanations for the improvements of these deficits in smooth pursuit eye movements include: (1) nicotine derived from the cigarettes acts as a cholinergic agonist to correct a defect in cholinergic neurotransmission that causes eye movement dysfunction, (2) smoking relieves the effect of nicotine withdrawal, or (3) nicotine improves the general level of attention, which then facilitates a secondary improvement in eye tracking function.

The findings of this study can be compared to those of a previous study by Klein and Andresen (1991), which also examined the effect of cigarette smoking on smooth pursuit eye movements in schizophrenic patients and normal subjects. This study found that the number of large amplitude saccades $\left(>6^{\circ}\right)$ that disrupt tracking decreased with cigarette smoking in both schizophrenic patients and normal subjects. However, the effect of smoking in schizophrenic patients was somewhat variable, with only $62 \%$ showing a decrease in large amplitude saccades. The authors of that report concluded that the dose of nicotine (one cigarette), relative to the usual intake from smoking, may have been low, particularly for the schizophrenic patients, who smoked an average of 10 cigarettes per day more than the normal subjects and suggested further studies controlling for smoking rate and intensity. In the present study, schizophrenic patients consumed more cigarettes in the 10-min period compared to the nonschizophrenic subjects. Thus, the one cigarette in the Klein and Andresen study may indeed have been an inadequate dose for the schizophrenic patients.

Two other studies have examined the effect of smoking on SPEM in nonschizophrenic subjects. Sibony et al. (1988), studied SPEM in normal subjects. They found that the horizontal smooth pursuit gain did not change after smoking, but square-wave saccades frequently intruded on smooth eye movements. These authors interpreted their findings as due to a nicotine-induced vestibular-type nystagmus effect on normal smooth pursuit.
Thaker et al. (1991) replicated the Sibony study with a larger number of subjects. They found a $38 \%$ increase in square-wave jerks during pursuit eye movements after smoking. All other eye movements, including global SPEM score (from 1 to 5,1 being the best), remained unaffected by smoking. The present study did not find any significant changes in square-wave jerks with smoking in either group, primarily due to the baseline variability of the measure and the low frequency of square-wave jerks observed.

One possible explanation of the difference in effects observed in schizophrenic patients and nonschizophrenic subjects in this study is the higher nicotine dose consumed by the schizophrenic subjects. However, the nonschizophrenic subjects who consumed more than one cigarette actually increased their leading saccades, and the nonschizophrenic subjects who consumed more than two cigarettes decreased their smooth pursuit gain and increased their catch-up saccades, which suggests that greater exposure to nicotine may diminish performance. Thus, a dose effect alone is an unlikely explanation of the benefit of nicotine. Rather, a group effect with high doses specifically benefiting the schizophrenic patient group is more plausible.

Schizophrenic patients smoke at prevalence rates between $74 \%$ and $92 \%$ compared to $35 \%$ to $54 \%$ for all psychiatric patients and $30 \%$ to $35 \%$ for the general population (Lohr and Flynn 1992). This elevated smoking rate is found even when known confounders, such as marital status, alcohol use, and socioeconomic status are controlled (Lohr and Flynn 1992). Schizophrenic smokers are also more likely to use high nicotine cigarettes (Lohr and Flynn 1992) and to extract more nicotine from cigarettes even when smoking the same number of cigarettes as nonschizophrenic smokers (Olincy et al. 1997). As nicotine appears to reduce neurolepticinduced extrapyramidal side effects, some have speculated that smoking is associated with neuroleptic treatment (Miller 1977). However, heavy smoking was found to be related to a diagnosis of schizophrenia, independent of neuroleptic treatment (de Leon et al. 1995). Smoking has been proposed to be a form of selftreatment for patients with schizophrenia, based on the hypothesis that nicotine corrects a neuronal defect involved in the pathophysiology of schizophrenia (Goff et al. 1992). Although schizophrenics' heavier smoking could be the result of metabolic or central nervous system tolerance induced by their long exposure to nicotine, their increased intake could also reflect their attempt to use nicotine from cigarettes to achieve a specific pharmacodynamic effect.

The marked effects of cigarette smoking on leading saccades in schizophrenia may have additional significance because of evidence that suggests that this physiological abnormality is a phenotype for part of the inherited risk for the illness. In families of schizophrenic 
probands, the parents who have ancestral histories of schizophrenia also have levels of leading saccades that are similar to those of the schizophrenic probands themselves (Ross et al. 1994). Schizophrenic probands' parents without such ancestral histories have normal levels of leading saccades. Thus, the apparent parental carrier of genetic risk expresses the leading saccade phenotype. Another group of presumed gene carriers is the children of schizophrenic mothers. Half of these children have levels of leading saccades that are greater than the range of values from normal children (Ross et al. 1996). Finally, in one of the pedigrees that showed genetic linkage for the P50 auditory-evoked potential abnormality, there is similar linkage or leading saccades (Olincy et al. 1997). Both the P50 and the leading saccade phenotypes are linked to D15S1360, a polymorphism isolated from a yeast artificial chromosome that contains the $\alpha-7$ nicotinic receptor (Freedman et al. 1997). In none of these studies of heritability were there similar results for any other parameter of eye movement disfunction.

Levin et al. (1982) and Litman et al. (1994) suggested that these leading saccades represent failure of prefrontal cortical areas to inhibit generation of inappropriate saccades by the superior colliculus. The schizophrenic patients use of nicotine may thus reflect a specific pharmacological attempt to maximize prefrontal inhibition. Similarly, the effects of nicotine on the P50 gating phenotype appear to involve an enhancement of inhibition, mediated through nicotinic receptors associated with GABAergic interneurons (Freedman et al. 1994).

An alternative explanation for the improvement in SPEM after smoking is that a nicotine withdrawal state, induced by the pretrial abstinence period, was relieved by smoking cigarettes. Contrary to this hypothesis, baseline smooth pursuit gain, percentage of eye movements due to leading saccades and percentage of eye movements due to catch-up saccades in these nicotineabstaining subjects are similar to values obtained in nonabstaining schizophrenic subjects (Radant and Hommer 1992 [small anticipatory saccades]) suggesting that SPEM abnormalities are not induced by nicotine withdrawal. The schizophrenic patients and the nonschizophrenic subjects demonstrated no obvious differences in anxiety or nicotine withdrawal as there were no differences between groups on baseline measures of pulse, systolic, or diastolic blood pressure and no relation of length of abstinence to baseline autonomic measures. The lack of changes from presmoking to postsmoking in pulse, systolic, or diastolic blood pressure in either group suggest that smoking did not relieve an acute withdrawal state in which symptoms are usually associated with autonomic changes. Length of abstinence also showed no relationship to the changes in gain or the percentage of total eye movements due to leading saccades or catch-up saccades from baseline in the schizophrenic patients, indicating that a longer withdrawal period did not worsen gain or increase the percentage of total eye movements due to leading and catch-up saccades in the nonsmoking condition or improve gain and decrease the percentage of total eye movements due to leading saccades and catch-up saccades with smoking.

Nicotine could also be acting in a nonspecific way to enhance attention. As nicotine is generally arousing and facilitates attentional processes (Wesnes and Wharburton 1984), both the schizophrenic patients and the nonschizophrenic subjects performance should improve after smoking. Indeed, the nonschizophrenic group had a trend toward decreased smooth pursuit gain without smoking by the fourth trial. The schizophrenic group demonstrated a trend toward a decline in smooth pursuit gain without smoking at an earlier time point, by the third trial. With smoking, the schizophrenic patients show a trend toward improved smooth pursuit gain and the nonschizophrenic subjects maintained their close to maximal baseline smooth pursuit gain. Thus, generalized affects of nicotine on attention may improve smooth pursuit gain after smoking in addition to the more specific effects on leading saccades. The cholinergic receptor subtypes and other neurobiological mechanisms associated with each of these effects remains to be determined.

\section{ACKNOWLEDGMENT}

This research was supported by N-A-R-S-A-D, the Veterans Administration Medical Research Service, and USPHS Grants MH4212, MH38321.

\section{REFERENCES}

Abel LA, Hertle RW (1988): Effects of psychoactive drugs on ocular motor behavior. In Johnston CW, Pirozzolo FJ (eds), Neuropsychology of Eye Movements. Hillsdale, NJ, Lawrence Erlbaum Associates, pp 81-114

Abel L, Friedman L, Jesberger J, Malki A, Melzer HY (1991): Quantitative assessment of smooth pursuit gain and catch-up saccades in schizophrenia and affective disorders. Biol Psychiatry 29:1063-1072

Adler LE, Hoffer LD, Griffith J, Waldo MC, Freedman R (1992): Normalization by nicotine of deficient auditory sensory gating in the relatives of schizophrenics. Biol Psychiatry 32:607-616

Adler LE, Hoffer LD, Wiser A, Freedman R (1993): Normalization of auditory physiology by cigarette smoking in schizophrenic patients. Am J Psychiatry 150:1856-1861

American Psychiatric Association (1987): Diagnostic and Statistical Manual of Mental Disorders, 3rd ed. revised. Washington, DC, American Psychiatric Association

Benowitz NL, Porchet H, Sheiner L, Jacob III P (1988): Nico- 
tine absorption and cardiovascular effects with smokeless tobacco use: Comparison with cigarettes and nicotine gum. Clin Pharmacol Ther 44:23-28

Clementz BA, Sweeney JA (1990): Is eye movement dysfunction a biological marker for schizophrenia? A methodological review. Psychol bull 108:77-92

Clementz BA, Grove WM, Iacono WG, Sweeney JA (1992): Smooth-pursuit eye movement dysfunction and liability for schizophrenia: implications for genetic modeling. J Abnorm Psych 101:117-129

de Leon J, Dadvand M, Canuso C, White AO, Stanilla JK, Simpson GM (1995): Schizophrenia and smoking: an epidemiological survey in a state hospital. Am J Psychiatry 152:453-455

Endicott J, Andreasen N, Spitzer RL (1978): Family HistoryResearch Diagnostic Criteria, 3rd ed. New York, Research. Assessment and Training Unit, New York State Psychiatric Institute

Freedman R, Adler LE, Bickford P, Byerley W, Coon H, Cullum CM, Griffith JM, Harris JG, Leonard S, Miller CM, Myles-Worsley M, Nagamoto HT, Rose G, Waldo M (1994): Schizophrenia and nicotinic receptors. Harvard Rev Psychiatry 2:179-192

Freedman R, Hall M, Adler LE, Leonard S (1995): Evidence in postmortem brain tissue for decreased numbers of hippocampal nicotinic receptors in schizophrenia. Biol Psychiatry 38:22-33

Freedman R, Coon $\mathrm{H}$, Myles-Worsley M, Orr-Utreger A, Olincy A, Davis A, Polymeropoulos M, Holik J, Hopkins J, Hoff M, Rosenthal J, Waldo MC, Reimherr F, Wender P, Yaw J, Young D, Breese C, Adams C, Patterson D, Adler LE, Kruglyak L, Leonard S, Byerley W (1997): Linkage of a neurophysiological deficit in schizophrenia to a chromosome 15 locus. Proc Natl Acad Sci 94:587--592

Friedman L, Jesberger JA, Meltzer HY (1991): A model of smooth pursuit performance illustrates the relationship between gain, catch-up saccade rate, and catch-up saccades amplitude in normal controls and patients with schizophrenia. Biol Psychiatry 30:537-556

Friedman L, Jesberger JA, Melzer HY (1992): Effect of typical antipsychotic medication and clozapine on smooth pursuit performance in patients with schizophrenia. Psychiatry Res 41:25-36

Goff DC, Henderson DC, Amico E (19,2): Cigarette smoking in schizophrenia: relationship to psychopathology and medication side effects. Am J Psychiatry 149:1189-1194

Grove WM, Clementz BA, Iacono WG, Katsanis J (1992): Smooth pursuit ocular motor dysfunction in schizophrenia: evidence for a major gene. Am J Psychiatry 149: 1362-1368

Holzman PS, Solomon CM, Levin S, Waternaux CS (1984): Pursuit eye movement dysfunctions in schizophrenia. Arch Gen Psychiatry 41:136-139

Holzman PS (1987): Recent studies of psychophysiology in schizophrenia. Schizophr Bull 13:49-75

Holzman PS, Kringlen E, Matthysse S, Flanagan SD, Lipton RB, Cramer G, Levin S, Lange K, Levy DL (1988): A single dominant gene can account for eye tracking dysfunctions and schizophrenia in offspring of discordant twins. Arch Gen Psychiatry 45:64] -647
Hughes JR, Hatsukami DK, Mitchell JE, Dahlgren LA (1986): Prevalence of smoking among psychiatric outpatients. Am J Psychiatry 143:993-997

Klein C, Andresen B (1991): On the influence of smoking upon smooth pursuit eye movements of schizophrenics and normal controls. J Psychophysiology 5:361-369

Laird NM, Ware JH (1982): Random-effects models for longitudinal data. Biometrics 38:963-974

Levin S, Jones A, Stark L, Merrin EL, Holzman PS (1982): Identification of abnormal patterns in eye movements of schizophrenic patients. Arch Gen Psychiatry 39:1125-1130

Levy DL, Yasillo NJ, Dorus E, Shaughnessy R, Gibbons RD, Peterson J, Janicak PG, Gaviria M, Davis JM (1983): Relatives of unipolar and bipolar patients have normal pursuit. Psychiatry Res 10:285-293

Levy DL, Lipton RB, Yasillo NJ, Peterson J, Pandey G, Davis JM (1984): Psychotropic drug effects on smooth pursuit eye movements: A summary of recent findings. In Gale AG, Johnson F (eds), Theoretical and Applied Aspects of Eye Movement Research. Amsterdam, Elsevier Publishing Co. pp 497-505

Levy DL, Holzman PS, Matthysse S, Mendell NR (1993): Eye tracking dysfunction and schizophrenia: A critical perspective. Schizophr Res 19:461-536

Lisberger SG, Pavelko TA (1989): Topographic and directional organization of visual motion inputs for initiation of horizontal and vertical smooth eye pursuit eye movements in monkeys. J Neurophysiol 61:173-185

Litman RE, Hommer DW, Radant A, Clem T, Pickar D (1994): Quantitative effects of typical and atypical neuroleptics on smooth pursuit eye tracking in schizophrenia. Schizophr Res 12:107-120

Lohr JB, Flynn K (1992): Smoking and schizophrenia. Schizophr Res 8:93-102

Luntz-Leybman V, Bickford PC, Freedman R (1992): Cholinergic gating of response to auditory stimuli in rat hippocampus. Brain Res 587:130-136

Miller RR (1977): Effects of smoking on drug action. Pharmacol Ther 2:749-756

Olincy A, Young DA, Freedman R (1997): Increased levels of the nicotine metabolite cotinine in schizophrenic smokers compared to other smokers. Biol Psych 42:1-5

Olincy A, Ross RG, Leonard S, Freedman R (1997): Preliminary linkage of eye movement abnormalities in schizophrenia. Society for Biological Psychiatry (Abstracts)

Radant AD, Hommer DW (1992): A quantitative analysis of saccades and smooth pursuit during visual pursuit tracking: A comparison of schizophrenics with normals and substance abusing controls. Schizophr Res 6:225-235

Ross RG, Harris J, Cullum CM, Rilling LM, Radant AD, Adler, LE, Freedman RF (1994): Smooth pursuit eye movements in parents of probands with schizophrenia: An obligate carrier approach. Society for Neuroscience (Abstracts) 20:1262

Ross RG, Hommer D, Radant A, Roath M, Freedman R (1996): Early expression of smooth-pursuit eye movement abnormalities in children of schizophrenic parents. J Am Acad Child Adolesc Psychiatry 35:941-949

Seber GAF, Wild CJ (1989): Nonlinear Regression. New York, John Wiley \& Sons 
Shallo-Hoffman J, Peterson J, Muhlendyck H (1989): How normal are "normal" square wave jerks? Investigative Opthalmol \& Visual Sci 30:1009-1011

Sibony PA, Evinger C, Manning KA (1988): The effects of tobacco smoking on smooth pursuit eye movements. Ann Neurol 23:238-241

Spitzer RL, Williams JBW, Gibbon M, First MB (1990): Structured Clinical Interview for DSM-III-Ki-Nonpatient Edi- tion (SCID-NP, Version 1.0). Washington, DC, American Psychiatric Press

Thaker GK, Ellsberry MM, Lahti A, Tamminga C (1991): Tobacco smoking increases square-wave jerks during pursuit eye movements. Biol Psychiatry 29:82-88

Wesnes K, Wharburton DM (1984): Effects of scopolamine and nicotine on human rapid information processing performance. Psychopharmacology 82:147-150 